\title{
Classic hybrid evolving approach to distal arch aneurysms: Toward the zone zero solution
}

\author{
Joseph Bavaria, MD, Rita K. Milewski, MD, PhD, Joshua Baker, MD, Patrick Moeller, \\ Wilson Szeto, MD, and Alberto Pochettino, MD
}

\begin{abstract}
Background: A combined open surgical and endovascular approach to managing aneurysms of the distal aortic arch (hybrid arch repair) is evolving as a viable treatment option. Our aim is to describe a treatment strategy in high-risk patients and report the technical and clinical success of the hybrid approach to aneurysms involving the distal aortic arch.
\end{abstract}

Methods: From July 2005 until December 2009, 27 consecutive patients with aneurysms of the distal aortic arch were treated via a hybrid arch repair. Of this group, 23 patients underwent aortic arch debranching and revascularization before endovascular stent deployment in the ascending aorta (type I). Four patients required ascending aortic and transverse arch replacement before stent graft deployment (type II).

Results: A stent graft was successfully deployed in $100 \%$ of patients after aortic arch vessel debranching via median sternotomy. The mean age of the patients was $71 \pm 7.5$ years. The average cardiopulmonary bypass time was $199 \pm 84$ minutes with an average crossclamp time of $57 \pm 53$ minutes. Deep hypothermic circulatory arrest was required in 4 patients (all type II). The average length of stay was $17.2 \pm 14$ days. The complications included stroke in $3(11 \%)$ patients, permanent paralysis in $2(7 \%)$, and perioperative death in $3(11 \%)$ patients.

Conclusions: Early results of type I and II hybrid arch repair, in this cohort of patients with mutiple comorbid risk factors, are acceptable and even encouraging. This evolving approach to aneurysms involving the aortic arch may extend the indications for use of endovascular prostheses in the treatment of patients with complex aortic arch disease. (J Thorac Cardiovasc Surg 2010;140:S77-80)

Aortic arch replacement for extensive and complex arch disease is technically challenging. Open total arch and total arch plus descending aortic procedures can be accomplished electively with complex circulatory management and adjunct cerebral protection. However, these procedures, especially when staged, have been associated with significant and sometimes prohibitive morbidity and mortality for those patients with multiple comorbidities. ${ }^{1-6}$

Thoracic endovascular repair has emerged as a treatment alternative for uncomplicated aortic disease of the descending thoracic aorta with acceptable midterm morbidity and mortality, and recently endovascular repair has been advocated for complicated aortic disease including type A dissections. ${ }^{1,2,7-10}$ The hybrid arch repair combines an open procedure to secure a proximal landing zone with concomitant antegrade endovascular stent graft placement in the aortic arch. Recent reports have demonstrated the

\footnotetext{
From the Hospital of the University of Pennsylvania, Department of Surgery, Philadelphia, Pa.

Disclosures: Joseph Bavaria is a member of the speakers bureau for Vascutek Terumo, and receives grant/research support from Gore \& Associates, Inc, and Medtronic, Inc, Vascular Therapy Division. Rita K. Milewski, Joshua Baker, Patrick Moeller, Wilson Szeto, and Alberto Pochettino have nothing to disclose with regard to commercial support Received for publication May 20, 2010; accepted for publication July 12, 2010.

Address for reprints: Joseph Bavaria, MD, Hospital of the University of Pennsylvania,

Department of Surgery, 34th and Spruce St, 4 Silverstein, Philadelphia, PA 19104

(E-mail: joseph.bavaria@uphs.upenn.edu). 0022-5223/\$36.00

Copyright (C) 2010 Published by Elsevier Inc. on behalf of The American Association for Thoracic Surgery

doi:10.1016/j.jtcvs.2010.07.031
}

feasibility of these procedures, with acceptable mortality and neurologic outcomes. ${ }^{1,7,9,10}$

Appropriate selection of patients is essential when considering an endovascular versus open aortic approach for complex aortic arch disease. We prefer the hybrid approach when multiple comorbidities make a traditional open repair high risk. This study evaluates the outcomes of a contemporary series of procedures from one institution for extensive aortic arch disease: open total arch, total arch plus descending aorta, and hybrid arch repairs (types I and II).

\section{METHODS \\ Patient Characteristics}

From 2005 to 2009 , we performed 81 hybrid endovascular procedures via sternotomy. Forty-five were emergency DeBakey I dissections with a distal stented elephant trunk, and 9 patients received concomitant ascending and extended arch replacement, with staged stent graft placement (either during the same hospital stay or on a second admission). Twenty-seven were classic elective open brachiocephalic debranching procedures with concomitant endovascular stent graft placement (hybrid arch). Hybrid arch procedures included 23 patients undergoing brachiocephalic debranching with endovascular sten graft placement alone (type I hybrid) and 4 patients with concomitant ascending arch replacement (type II hybrid) to establish a suitable proximal landing zone. The type III hybrid includes the previously mentioned 9 patients undergoing concomitant ascending and extended arch replacement with staged stent graft placement: these were not included in this analysis. Mean age was $71.2 \pm 7.5$ years. The mean maximum size of atherosclerotic aneurysm was $7.4 \pm 1.7 \mathrm{~cm}$. Preoperative patient characteristics are summarized in Table 1.

\section{Surgical Technique}

For arch aneurysms treatable with a type I hybrid reconstruction (the classic debranching procedure), the procedure was performed with 
TABLE 1. Preoperative characteristics

\begin{tabular}{|c|c|c|c|c|c|c|}
\hline Preoperative characteristics & \multicolumn{2}{|c|}{ Hybrid } & \multicolumn{2}{|c|}{ Type 1} & \multicolumn{2}{|c|}{ Type 2} \\
\hline $\mathbf{N}$ & \multicolumn{2}{|c|}{27} & \multicolumn{2}{|c|}{23} & \multicolumn{2}{|c|}{4} \\
\hline Age (y) & 71.2 & \pm 7.5 & 70.5 & \pm 8.7 & 75.0 & \pm 4.3 \\
\hline Gender ( $\mathrm{N}$ male) & 18 & $67 \%$ & 0 & $0 \%$ & 0 & $0 \%$ \\
\hline Prior CVA & 12 & $44 \%$ & 10 & $43 \%$ & 2 & $50 \%$ \\
\hline Prior MI & 5 & $19 \%$ & 5 & $22 \%$ & 0 & $0 \%$ \\
\hline CRI & 5 & $19 \%$ & 0 & $0 \%$ & 0 & $0 \%$ \\
\hline Smoker & 22 & $81 \%$ & 19 & $83 \%$ & 3 & $75 \%$ \\
\hline \multicolumn{7}{|l|}{ Type of disease } \\
\hline Aneurysm & 26 & $96 \%$ & 22 & $96 \%$ & 4 & $100 \%$ \\
\hline Fusiform & 5 & $19 \%$ & 3 & $13 \%$ & 2 & $50 \%$ \\
\hline Saccular & 21 & $78 \%$ & 19 & $83 \%$ & 2 & $50 \%$ \\
\hline Maximum diameter (mean, $\mathrm{cm}$ ) & 7.4 & \pm 1.7 & 7.3 & \pm 1.7 & 8.6 & \pm 0.8 \\
\hline Pseudoaneurysm (posttraumatic transection) & 1 & $4 \%$ & 1 & $4 \%$ & & \\
\hline
\end{tabular}

$C V A$, Cerebrovascular accident; $M I$, myocardial infarction; $C R I$, chronic renal insufficiency.

a 4-branched Dacron graft anastomosed in an end-to-side fashion along the greater curve of the ascending aorta, just distal to the sinotubular junction, to allow deployment of the stent graft in the ascending aorta without compromise of the proximal inflow anastomosis. When performed off bypass (type IA, $n=7$ ), a side-biting clamp was used on the ascending aorta. If a limited amount of aorta existed between the sinotubular junction and the ascending aorta, full cardiopulmonary bypass with aortic crossclamping and cardiac arrest using standard cardioplegia was required (type $I B, n=15$ ).

For patients undergoing a type II repair, deep hypothermic circulatory arrest was used. A segment of aorta just distal to the sinotubular junction was identified for the proximal anastomosis, and normalization of the sinotubular junction was performed with the 4-branched aortic graft. After profound hypothermia and a flat electroencephalogram had been achieved, retrograde cerebral perfusion was initiated, and the aortic arch was opened. Retrograde cerebral perfusion was usually performed for a brief period before selective antegrade cerebral perfusion while the proximal aortic arch was prepared for the hybrid procedure. After complete dissection of the brachiocephalic vessels from the aortic arch, the distal aortic arch anastomosis was completed. For all hybrid arch procedures, the distal end-to-end anastomosis of the branched grafts to the arch vessels was sequentially performed for the left subclavian, left common carotid, and innominate arteries. The proximal takeoff of each arch vessel was detached with a stapling device. Deairing maneuvers were performed for each anastomosis before release of the distal clamp. The Gore TAG thoracic endoprosthesis (W.L. Gore \& Associates, Inc, Flagstaff, Ariz) was used in 24 of 27 patients. One Medtronic Talent device (Medtronic, Inc, Minneapolis, Minn) and 2 Cook TX2 devices (Cook Medical, Bloomington, Ind) were used in the remaining patients. The stent-graft devices were deployed under fluoroscopy, and completion angiography was performed in all cases. Deployment of the stent graft was successful in $100 \%$ of cases. The average endovascular pavement length for type I was $26.8 \pm 8.5 \mathrm{~cm}$; it was $31.3 \pm 21.4 \mathrm{~cm}$ for type II.

\section{RESULTS}

Ninety-six percent of patients undergoing the classic hybrid procedure had atherosclerotic disease. Saccular atherosclerotic disease was prevalent in patients undergoing hybrid procedures $(78 \%)$ (Table 1$)$. Intraoperative variables are described in Table 2.

Transient reversible spinal cord ischemia occurred in 3 $(11 \%)$ hybrid arch procedures. Two $(7 \%)$ patients undergoing the hybrid arch procedure had new postoperative paraplegia develop, and both died before hospital discharge. Permanent cerebral neurologic deficits, embolic in origin, occurred in $3(11 \%, 1$ death) patients in the hybrid arch group. Other outcomes are described in Table 3.

Thirty-day mortality was $11 \%$. When stratified by age, there are no significant differences for in-hospital mortality between groups: patients less than 75 years (1 death, 12 patients, $6 \%$ ) and patients more than 75 years (2 deaths, 15 patients, $16 \%$ ) did not have significantly different rates of death. Age was not a factor for neurologic deficit or postoperative renal failure. No endoleaks occurred in any patient $(0 \%)$. Mean length of follow up was $20.5 \pm 17.4$ months.

\section{DISCUSSION}

Although operative approaches for complex aortic diseases have evolved over the past 25 years, an optimal

TABLE 2. Operative times

\begin{tabular}{|c|c|c|c|c|c|c|}
\hline Intraoperative & \multicolumn{2}{|c|}{ Hybrid } & \multicolumn{2}{|c|}{ Type 1} & \multicolumn{2}{|c|}{ Type 2} \\
\hline $\mathbf{N}$ & \multicolumn{2}{|c|}{27} & \multicolumn{2}{|c|}{23} & \multicolumn{2}{|c|}{4} \\
\hline Off pump & 7 & $26 \%$ & 7 & $30 \%$ & & \\
\hline CPB time & 199.5 & \pm 84.0 & 179.9 & \pm 75.2 & 278.0 & \pm 47.5 \\
\hline Clamp time & 57.9 & \pm 53.0 & 42.3 & \pm 29.2 & 120.3 & \pm 75.7 \\
\hline Arrest? & 4 & $15 \%$ & 0 & $0 \%$ & 4.0 & $100 \%$ \\
\hline Arrest time (total, min) & 64.5 & \pm 14.5 & & & 64.5 & \pm 14.5 \\
\hline RCP time (min) & 13.5 & \pm 6.0 & & & 13.5 & \pm 6.0 \\
\hline ACP time (min) & 51.0 & \pm 10.9 & & & 51.0 & \pm 10.9 \\
\hline
\end{tabular}

$C P B$, Cardiopulmonary bypass; $R C P$, retrograde cerebral perfusion; $A C P$, antegrade cerebral perfusion. 
TABLE 3. Postoperative outcomes

\begin{tabular}{|c|c|c|c|c|c|c|}
\hline Outcomes & \multicolumn{2}{|c|}{ Hybrid } & \multicolumn{2}{|c|}{ Type 1} & \multicolumn{2}{|c|}{ Type 2} \\
\hline $\mathbf{N}$ & & & & & & \\
\hline Thirty-day mortality & 3 & $11 \%$ & 3 & $13 \%$ & 0 & \\
\hline Stroke & 3 & $11 \%$ & 3 & $13 \%$ & 0 & \\
\hline Permanent paraplegia & 2 & $7 \%$ & 2 & $9 \%$ & & \\
\hline Transient neurologic deficit & 3 & $11 \%$ & 2 & $9 \%$ & 1 & $25 \%$ \\
\hline Renal failure & 2 & $7 \%$ & 2 & $9 \%$ & 0 & \\
\hline Renal failure requiring new hemodialysis & 1 & $4 \%$ & 1 & $4 \%$ & 0 & \\
\hline Reop for bleeding & 0 & $0 \%$ & & & & \\
\hline Atrial fibrillation & 12 & $44 \%$ & 10 & $43 \%$ & 2 & $50 \%$ \\
\hline Mean hospital stay (d) & 17.2 & \pm 14.0 & 16.3 & \pm 14.0 & 22.0 & \pm 9.6 \\
\hline
\end{tabular}

surgical technique has not been definitively established. Although the results of open total arch repair have improved, the morbidity and mortality associated with conventional repair using cardiopulmonary bypass and deep hypothermic circulatory arrest are not insignificant. For complicated aortic arch disease in patients with multiple prohibitive comorbid- ities, the hybrid procedure can be performed with acceptable morbidity and mortality. 1,7,9,10 This complex aortic disease requires precise management and often modification of landing zones for endovascular placement. $1,7,10$

In our series, for patients with type I saccular arch disease $(\mathrm{n}=17)$ with suitable native proximal and distal landing

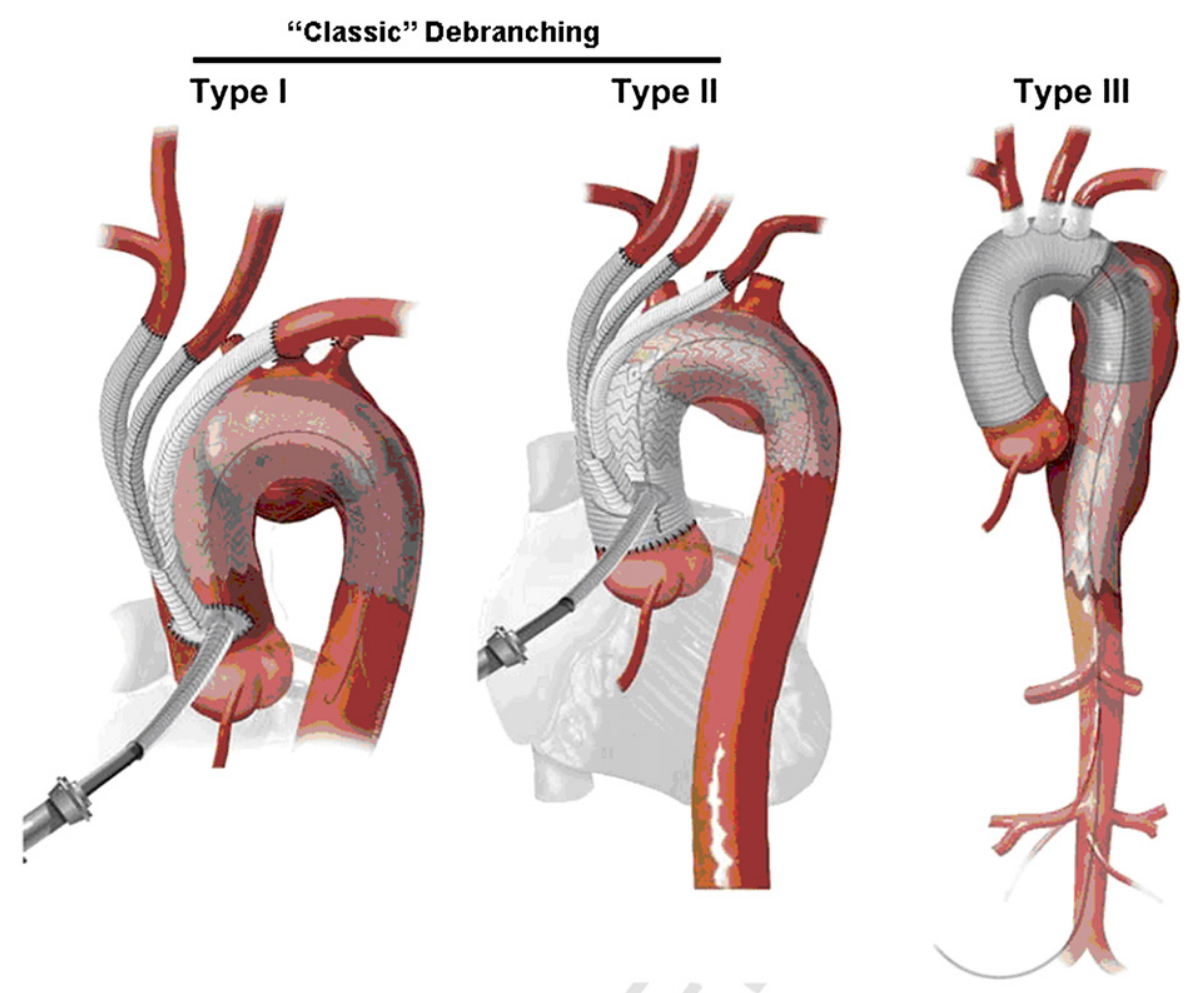

FIGURE 1. Type I aortic disease. For type I saccular arch aneurysm, the classic debranching procedure can be performed to bypass the cerebral vessels. This procedure involves the end-to-side anastomoses of a 4-branched graft to the ascending aorta. This can be done off bypass with a side-biting clamp on the ascending aorta (IA). If a limited amount of aorta exists between the sinotubular junction and the ascending aorta, full cardiopulmonary bypass with crossclamp is required (IB). Type II aortic arch disease. This aortic disease has no adequate suitable native proximal aorta but has a distal aorta for antegrade deployment of the endovascular graft. However, this pathologic condition requires construction of a landing zone 0 site with a 4-branched graft. Type III aortic arch disease. For type III aortic arch disease, or mega-aorta, there is no adequate suitable native proximal ascending or descending aorta. The inadequate suitable distal native aorta extends to just proximal to the celiac artery. Mega-aorta also requires reconstruction of a landing zone 0 site with a 4-branched graft. The remaining mega-aorta is addressed by thoracic endovascular aortic repair during the same hospitalization (IIIA). In some cases, an interval between the open debranching procedure and completion of aneurysmal exclusion with further endovascular stent grafting is required (IIIB). 
zones, the classic debranching procedure using a 4-branched graft and antegrade deployment of the endovascular stent into the native ascending aorta was performed either off (type IA) or on (type IB) cardiopulmonary bypass. For type II arch disease $(n=2)$ (with an unsuitable proximal landing zone but suitable distal landing zones), ascending aortic reconstruction of landing zone 0 with the 4-branched graft and endovascular stent deployment into the Dacron ascending aorta was performed. The types of hybrid procedures are illustrated in Figure 1.

Analysis of the 27 patients with a classic hybrid arch revealed that $96 \%$ had atherosclerotic aneurysms. No endoleaks occurred in our series. The overall mortality was $11 \%$ in this cohort of patients. This is consistent with mortality seen in other hybrid series $(0 \%-15 \%))^{1,7,9-11}$ In our classic hybrid arch group, the incidence of permanent cerebral neurologic deficit was $11 \%$. Paraplegia occurred in $2(7 \%)$ patients and is consistent with other hybrid series, which report a $0 \%$ to $10 \%$ incidence of paraplegia. ${ }^{1,7,9-11}$ Both of these patients were treated early in our series: one had extensive aneurysmal disease including abdominal aortic aneurysm requiring distal stent deployment to the celiac artery. Extensive endovascular stent placement in conjunction with abdominal aortic aneurysm has been associated with spinal cord injury. ${ }^{11}$

Atherosclerotic disease is a predictor of perioperative stroke. $^{4,12}$ Delineation of atherosclerotic aneurysms in patients undergoing hybrid procedures revealed that $78 \%$ (21/27) were saccular arch aneurysms. Previously, these patients have been considered to be at prohibitively high risk for conventional open arch repair owing the associated high stroke risk. Recent series of total arch repair for large atherosclerotic arch aneurysms still report in-hospital mortality ranging from $6.3 \%$ to $20 \%$ and an incidence of stroke up to $12 \% .^{1,3,4,6,12}$ Atherosclerotic burden was defined as high grade or mobile atheroma in $52 \%(14 / 27)$ of patients. In our series, the overall incidence of permanent cerebral neurologic deficit was $8 \%$.

An algorithmic approach to patient selection and operative approach — whether hybrid or open arch repair-must be based on presenting comorbidities such as a significant smoking history, moderate to severe chronic obstructive pulmonary disease, saccular aneurysm with significant atherosclerotic burden, and high-grade or mobile atheroma. As older populations with additional comorbidities present with aortic pathologic conditions, innovative methods of treatment must be developed to achieve acceptable outcomes.

Selection criteria for hybrid procedures are based on age, aortic disease, and comorbidities. For this cohort, they included aneurysms shown on computed tomographic angiography as either saccular or with significant atherosclerotic burden and transesophageal echocardiographic/computed tomographic evidence of high-grade or mobile atheroma.
The selection criteria also included many patients with significant smoking history and moderate to severe chronic obstructive pulmonary disease who would not likely tolerate a left thoracotomy or a thorocosternotomy; those with chronic renal failure and patients with other comorbidities who would not tolerate an open staged procedure; as well as patients with significant preoperative neurologic compromise (previous cerebrovascular accident or paraplegia). Exclusion criteria for hybrid arch reconstruction include younger patients, patients with vascular disease such as Marfan syndrome, and those with infection.

\section{CONCLUSIONS}

The hybrid arch repair for aortic arch aneurysms continues to evolve with improvement in perioperative morbidity and mortality. These data suggest that hybrid arch repairs are safe and effective for high-risk patients. The results of hybrid arch repairs must be measured against the results of proven conventional open surgical techniques. The limited data are encouraging although the enthusiastic application of this new technology must be tempered with caution. Larger series of hybrid arch repairs with longer follow-up must be examined before these techniques can be extended to patients with lower risk.

\section{References}

1. Szeto W, Bavaria JE, Bowen F, Woo E, Fairman R, Pochettino A. The hybrid total arch repair: brachiocephalic bypass and concomitant endovascular aortic arch stent graft placement. J Card Surg. 2007;22:97-102.

2. Svensson LG, Kim K, Blackstone E, Alster J, McCarthy P, Greenberg R, et al. Elephant trunk procedure: newer indications and uses. Ann Thorac Surg. 2004; 78:109-16.

3. Estrera A, Miller C, Porat E, Huynh T, Winnerkvist A, Safi HJ. Staged repair of extensive aortic aneurysms. Ann Thorac Surg. 2002;74:S1803-5.

4. Ergin MA, Galla J, Lansman S, Quintana C, Bodian C, Griepp R. Hypothermic circulatory arrest in operations on the thoracic aorta: determinants of operative mortality and neurologic outcome. J Thorac Cardiovasc Surg. 1994;107:788-92.

5. Svensson LG, Crawford ES, Hess KR, Coselli JS, Raskin S, Shenaq SA, et al. Deep hypothermia with circulatory arrest: determinants of stroke and early mortality in 656 patients. J Thorac Cardiovasc Surg. 1993;106:19-28.

6. Sundt TM, Orszulak TA, Cook DJ, Schaff HV. Improving results of open arch replacement. Ann Thorac Surg. 2008;86:787-96.

7. Hughes GC, Daneshmand MA, Balsara KR, Achneck HA, Sileshi B, Lee SM, et al. "Hybrid" repair of aneurysms of the transverse aortic arch: midterm results. Ann Thorac Surg. 2009;88:1882-7.

8. Pochettino A, Brinkman WT, Moeller P, Szeto WY, Moser GW, Cornelius K, et al. Proximal descending thoracic stent grafting via the open arch during standard repair for acute DeBakey I aortic dissection prevents development of dissecting thoracoabdominal aortic aneurysms. Ann Thorac Surg. 2009;88:482-9.

9. Czerny M, Zimpfer D, Fleck T, Hofmann W, Schoder M, Cejna M, et al. Initial results after combined repair of aortic arch aneurysms by sequential transposition of the supra-aortic branches and consecutive endovascular stent-graft placement. Ann Thorac Surg. 2004;78:1256-60.

10. Bavaria JE, Gaca JG, Szeto WY, Wallen TJ, Moser GW, Pochettino A. New conceptual approach to distal arch aneurysms: hybrid brachiocephalic debranching with TEVAR. 45th Annual Meeting; Society of Thoracic Surgeons; San Francisco: 2009 Jan; p. 311.

11. Flores J, Kunihara T, Shiiya N, Yoshimoto K, Matsuzaki K, Yasuda K. Extensive deployment of the stented elephant trunk is associated with an increased risk of spinal cord injury. J Thorac Cardiovasc Surg. 2006;131:336-42.

12. Gutsche JT, Cheung AT, McGarvey ML, Moser WG, Szeto W, Carpenter JP, et al. Risk factors for perioperative stroke after thoracic endovascular aortic repair. Ann Thorac Surg. 2007;84:1195-200. 